\title{
Poder Judiciário e políticas públicas de saúde: participação democrática e equidade
}

\author{
Daniel Wei Liang Wang ${ }^{1}$
}

RESUMO: Este artigo insere-se na discussão sobre a judicialização da saúde, especialmente sobre seus efeitos distributivos. A literatura existente aponta para os efeitos regressivos causados pela interferência judicial em políticas públicas de saúde, que beneficiaria apenas os já socialmente favorecidos. No diálogo com essa literatura, este trabalho tenta mostrar que o Judiciário pode ser uma via institucional onde os menos favorecidos podem se manifestar e transformar suas demandas em direitos judicialmente tutelados, o que é uma forma de manifestação democrática e de accountability das políticas públicas de saúde. O Judiciário pode ser complementar a outras formas de participação, mas isso só acontecerá se houver instituições que promovam o acesso à Justiça entre os menos favorecidos, como é o caso do Ministério Público e da Defensoria Pública. Um dos focos deste trabalho é analisar empiricamente como têm atuado essas instituições em matéria de proteção ao direito à saúde.

PALAVRAS-CHAVE: Poder Judiciário, políticas públicas, saúde, democracia, equidade.

ABSTRACT: This paper aims to contribute to the debate on the judicial protection of the right to health, especially in what concerns to its distributive effects. Some researchers have indicated that judicial activism in health policies have regressive effects because only those who are already socially well-off have information and resources to take their demands to courts. In contrast, this paper aims to show that Courts may be an institutional voice for the protection of the right to health for people with worse social and economic status, what promotes democracy and health policies accountability. Judiciary power may increase democratic participation, as long as institutions that promote access to Justice, like the Ministério Público and Defensoria Pública promote to the poor population. Analyzing empirically these two institutions allows to evaluate the role of Judiciary power in promoting health rights.

KEYWORDS: Judiciary Power, public policies, health, democracy, equity.

\footnotetext{
${ }^{1}$ Mestre em Direito Constitucional na Faculdade de Direito da Universidade de São Paulo e mestrando em Filosofia e Políticas Públicas pela London School of Economics and Political Science. E-mail: danielwei_cn@yahoo.com.br
} 


\section{Apresentação}

A relação existente entre baixa posição socioeconômica e más condições de saúde já é conhecida. Os socialmente menos favorecidos tendem a adoecer com maior frequência e têm acesso mais restrito a bens e serviços de saúde (TRAVASSOS et al, 2000, p. 144). Portanto, profundas iniquidades na distribuição de poder político e recursos econômicos são determinantes sociais da mais alta relevância para a iniquidade em saúde (CSDH, 2008, p. 1). Uma das explicações possíveis para essa relação está na incapacidade dos grupos menos favorecidos de se organizarem para vocalizar suas demandas e transformá-las em políticas públicas efetivas.

É sob essa perspectiva que este trabalho refletirá sobre a judicialização da saúde, um conceito usado para se referir ao uso de ações judiciais para obrigar o poder público a fornecer bens e serviços relacionados à saúde, o que inclui medicamentos, tratamentos, insumos, cirurgias, próteses, órteses, internações e melhoras de infraestrutura em unidades de saúde.

Essas ações têm em comum o fundamento jurídico para o pedido à Constituição Federal, que prevê o direito à saúde como um direito fundamental do cidadão e um dever do Estado (arts. $6^{\circ}$ e 196) e inaugura um sistema de saúde que tem entre seus princípios a universalidade (acesso a todos os cidadãos), a igualdade (não discriminação) e a integralidade (acesso a todos os níveis de complexidade) no atendimento (arts. 196 e 198).

A judicialização da saúde tem ocorrido com intensidade cada vez maior no Brasil, o que tem gerado impactos econômicos bastante significativos nas finanças públicas e um grande debate a respeito dos efeitos distributivos dessa atuação do Judiciário em matéria de políticas públicas de saúde.

Primeiramente, cabe notar que o gasto público com compra de medicamentos ordenada por via judicial tem crescido muito nos últimos tempos e seus valores estão longe de ser inexpressivos. Em 2007, o ministro da saúde do Brasil, José Gomes Temporão, afirmou que “os Estados (...) desembolsam, em média, R\$ 500 milhões por ano” para cumprimento de decisões judiciais (Folha de S. Paulo, 03.10.2005). Os gastos com medicamentos do Ministério da Saúde do Brasil originados por decisões judiciais aumentaram 211,4\% de 2005 a 2006, e em 2008 alcançaram a cifra de R\$ 52 milhões. Só no Estado de São Paulo, o governo gastou R\$ 86 milhões para fornecer medicamentos e tratamentos médicos em 
cumprimento de decisões judiciais, o que representa 30\% do gasto no programa oficial de remédios de alto custo (Folha de S. Paulo, 03.10.2005; 09.01.2009; 19.02.2009).

Há uma literatura recente, com forte embasamento empírico, que mostra que grande parte desses recursos acaba beneficiando aqueles já socialmente favorecidos, o que agravaria ainda mais as injustiças sociais no que toca ao acesso a bens e serviços de saúde. De acordo com essa literatura, pessoas com boa condição socioeconômica são as que têm acesso ao Judiciário e, por conseguinte, a decisões judiciais que lhes concedem bens e serviços públicos de saúde, o que coloca a questão de a judicialização da saúde ser ou não um mecanismo de injustiça distributiva.

Neste trabalho, tento mostrar que o Judiciário, dadas algumas circunstâncias, como a existência de instituições que promovam o acesso à Justiça, pode ser um espaço de participação democrática nas políticas públicas de saúde, principalmente para os menos favorecidos, que têm na tutela jurisdicional um importante espaço institucional onde reclamar bens e serviços de saúde não disponibilizados ou disponibilizados de forma deficiente pelo poder público.

\section{Judicialização da saúde e iniquidade na distribuição de recursos}

O debate sobre a judicialização da saúde deve partir da premissa de que o cenário de escassez de recursos é inescapável e as necessidades serão sempre maiores do que as possibilidades do orçamento público, o que parece óbvio para economistas e gestores públicos, mas nem sempre o é para juristas (WANG, 2007, p. 239). Dessa forma, escolhas devem ser feitas, pois não é possível prover todos os direitos sociais em grau máximo a todas as pessoas (FERRAZ, 2008). A questão é quem deve fazer essas escolhas, e os críticos da judicialização da saúde defendem que não deve ser o Judiciário a cumprir essa tarefa.

Primeiramente porque em um Estado democrático é indispensável que decisões sobre alocação de recursos sejam reservadas aos poderes políticos, pois estes foram democraticamente eleitos pelo povo para tanto e estão sujeitos a avaliações, principalmente nas eleições periódicas, o que não ocorre com os membros do Poder Judiciário. 
Outra crítica afirma que o caráter coletivo dos direitos sociais requer que políticas sejam pensadas coletivamente, o que os juízes, em regra, não fazem, principalmente porque não possuem informações essenciais para pensar uma política pública (SILVA, 2007) e também pela própria estrutura de um processo judicial, que se concentra no caso concreto objeto da disputa (AMARAL, 2001, p. 38).

Por conseguinte, uma atuação do Judiciário que favoreça indivíduos ou grupos em um caso concreto pode minar os esforços de um planejamento de política pública de longo prazo que beneficie um número maior de pessoas (SUNSTEIN e HOMES, 1999, p. 95; LOPES, 2006, p. 134-138). O juiz decide qual a melhor forma de se aplicar esses recursos escassos, mesmo sabendo pouco ou quase nada sobre a política pública em questão, as finanças públicas e a capacidade de gasto do poder público, ou a respeito de outros problemas sociais que competem por ação governamental (SUNSTEIN e HOMES, 1999, p. 95). Não há análise dos custos de oportunidade gerados por determinada decisão alocativa.

De acordo com essa linha de argumentação, a tarefa de alocar recursos escassos deve ser deixada para o processo político, pois ele possui maior “qualidade decisória”, no sentido de clareza das prioridades e dos meios para realizá-las (BUCCI, 1997, p. 97).

Outra crítica, ligada às já apresentadas, é a de que a judicialização da saúde gera iniquidade na distribuição de recursos porque uma quantia significativa do orçamento destinado ao sistema público de saúde é usufruída por uma parcela pequena e já favorecida da população.

Vieira e Zucchi (2007) analisaram ações judiciais com pedido de fornecimento de medicamentos movidos por cidadãos contra a Secretaria Municipal de Saúde de São Paulo, durante 2005, e concluíram que a maioria dos pacientes foi representada por advogados privados (54\%) e morava nas áreas do município com menor grau de exclusão (63\%), o que, para as autoras, indica iniquidade na distribuição de recursos.

Fernanda Terrazas (2008), por meio de entrevistas realizadas com pessoas que vão buscar medicamentos na Farmácia de Ação Judicial - uma estrutura física montada pela Secretaria de Saúde do Estado de São Paulo para atender exclusivamente pessoas que recebem medicamentos cujo fornecimento foi ordenado por via judicial -, mapeou a condição socioeconômica daqueles que conseguiram medicamentos por meio de uma ação judicial. Dentre as conclusões que os dados obtidos pela pesquisa apresentam: 
1. $60,63 \%$ dos solicitantes tiveram a prescrição do medicamento proveniente de estabelecimento de saúde privado; 26,25\% tiveram atendimento em estabelecimentos do SUS-Referência, que são normalmente ligados a alguma instituição de ensino superior e que se distinguem dos demais estabelecimentos do SUS por oferecerem, em regra, serviços considerados de excelência e por serem de acesso mais restrito; somente 13,13\% dos entrevistados são provenientes dos serviços públicos de saúde ordinários, ou seja, que atendem à maioria da população e não são centros de referência.

2. $60 \%$ dos beneficiados tiveram ação proposta por serviços particulares de advogados (38,75\%) ou associações/ONGs (21,25\%); 28,75\% pela Procuradoria de Assistência Judiciária; ${ }^{2}$ apenas 1,88\% pelo Ministério Público; e 9,38\% por outros meios.

3. Em relação à renda dos entrevistados, a autora identificou dois grupos: um primeiro, de baixa renda, proveniente do SUS e assistido pela Procuradoria de Assistência Judiciária, que requisita geralmente material de enfermagem e remédios mais simples, mas que aparece também nas ações com pedidos de medicamentos para diabetes. O segundo grupo é formado por pessoas de renda mais elevada, provenientes da rede privada de saúde, assessorados por advogados particulares e que solicitam remédios de custos mais elevados (dos medicamentos oncológicos, a prescrição foi feita em hospital particular em $84,38 \%$ dos casos) e insulinas mais modernas para diabetes.

A conclusão a que essa pesquisa chegou é que são os cidadãos privilegiados que fazem uso do Judiciário para conseguir medicamentos. São as pessoas com melhores condições socioeconômicas que conseguem usar o Judiciário para intervir na política pública de fornecimento de medicamentos.

\footnotetext{
${ }^{2}$ A Procuradoria de Assistência Judiciária é integrante da Procuradoria Geral de Justiça de São Paulo e, até a criação da Defensoria Pública em São Paulo, em 2006, era a única que prestava assistência jurídica gratuita.
} 


\section{Judiciário como espaço de participação democrática}

Em um Estado Democrático de Direito, é indispensável que decisões de alocação de recursos, para serem legítimas, sejam tomadas em processos de deliberação nos quais esteja garantida a participação e a contestação pública. Escolhas que envolvam justiça distributiva e alocação de recursos escassos possuem um caráter multilateral, pois dizem respeito à apropriação por alguns de bens financiados por toda a sociedade, o que reforça a importância da participação democrática na tomada dessas decisões.

Além de trazer maior legitimidade para as decisões, um processo democrático de decisão tem o condão de permitir a manifestação dos interesses tanto daqueles que contribuem quanto daqueles que se beneficiam, ou não, da rede de solidariedade social, além de promover um diálogo entre a sociedade civil e o Estado, responsável pela execução daquilo que foi decidido democraticamente.

Ligando a importância da participação democrática com o resultado das políticas públicas, Sen (2000, p. 178) defende que as liberdades civis e políticas, além de possuírem um valor intrínseco, proporcionam às pessoas a oportunidade de chamar a atenção eficazmente para suas necessidades e exigir a ação pública apropriada. De acordo com o autor, a resposta do governo ao sofrimento do povo frequentemente depende da pressão exercida sobre esse governo, e, nesse ponto, o exercício dos direitos políticos e civis (votar, criticar, protestar etc.) pode realmente fazer a diferença.

Na área da saúde, essa avaliação não é diferente. A Organização Mundial de Saúde reconhece que qualquer esforço sério para reduzir iniquidades em saúde deve passar pela distribuição de poder em uma sociedade, empoderando (empowering) indivíduos e grupos para representarem suas necessidades e interesses nas agendas das políticas públicas (CSDH, 2008, p. 18, 155-164).

O que tentarei mostrar nesta seção é que uma participação democrática maior para legitimar e dar mais eficácia para as políticas públicas, normalmente utilizadas como argumento contra a judicialização da saúde, pode perfeitamente ser utilizada para se defender à tese contrária, de que o Judiciário é uma instituição que permite maior participação, especialmente daqueles socialmente menos favorecidos.

Para isso, primeiramente, analisarei a participação democrática pela observação de algumas instituições existentes desenhadas para promovê-la para mostrar as limitações que possuem 
e como algumas das críticas direcionadas ao poder Judiciário podem ser estendidas a outras instâncias de participação. Posteriormente, mostrarei as vantagens comparativas que possui o Judiciário no que se refere à promoção da participação democrática.

\section{Democracia representativa e participação democrática}

Sen (2000, p. 180) dá como exemplo de instituição onde essa participação pode se manifestar e surtir efeito a democracia representativa por meio de eleições periódicas, porque os dirigentes políticos que precisam enfrentar a crítica do povo e buscar seu apoio nas eleições têm os incentivos para ouvir suas necessidades.

Dentro da perspectiva da democracia representativa, conforme visto na primeira seção deste trabalho, a judicialização da saúde é vista por alguns autores com muitas reservas e descrença nas suas possibilidades, pois preferem o processo político para concretizar direitos sociais.

Contudo, acredito que uma concepção de democracia e participação restrita à representação escolhida pelos cidadãos por meio de eleições periódicas é limitada. Embora a associação democracia/representatividade seja correta, uma vez que dificilmente pode haver um sistema de governo no mundo atual que possa ser chamado de democrático sem contar com algum grau de representatividade, acredito que há necessidade da existência de outros espaços institucionais nos quais a participação e a deliberação dos cidadãos no processo decisório de políticas públicas possam ocorrer.

Embora a democracia representativa permita a premiação e a punição dos eleitos por parte dos eleitores, ela nem sempre garante que aqueles que são afetados por algumas decisões em matéria de políticas públicas possam se manifestar e, de fato, terem alguma participação nas tomadas de decisão. Pode-se dizer que há dificuldade de se punir ou premiar um político em razão da qualidade de certa política pública, uma vez que as razões que determinam um voto são difíceis de se identificar e extrapolam o julgamento da população com relação a uma só política. Esse julgamento torna-se ainda mais complicado se pensarmos que uma política pública divide-se em várias fases: identificação de uma questão, estabelecimento de uma agenda, formulação, adoção, implementação, sua análise e avaliação (THEODOLOU, 1995, p. 86), o que dificulta a leitura, tanto por parte do eleitor quanto do eleito, daquilo que efetivamente se está punindo ou premiando. 
Além do mais, a democracia representativa não impede que desigualdades econômicas se reflitam em desigualdades na capacidade de influir em decisões políticas. Nem sempre os políticos competirão por votos oferecendo políticas que melhorem a vida dos menos favorecidos. E, dentre as razões para isso, vale citar alguns exemplos: 1) a dependência dos políticos de contribuições para suas campanhas (SHAPIRO, 2003, p. 108); 2) a influência de grupos de interesse organizados (SHAPIRO, 2003, p. 108; LAPALOMBARA, 1982, p. 239; SALISBURY, 1975, p. 221-223), o que inclui, por exemplo, lobbying, barganha por trás dos bastidores, propaganda e informação, e relacionamentos privilegiados (LAPALOMBARA, 1982, p. 310-323); 3) a preferência, ditada pela dinâmica da disputa eleitoral, por políticas de impacto imediato e com apelo midiático ao invés de programas eficientes de longo prazo; 4) raras medidas de sanção sobre os representantes que atuam de modo que seus eleitores consideram inadequados (GARGARELLA, 1995, p. 90); 5) limitação de informação do eleitor em relação à atuação dos representantes (GARGARELLA, 1998, p. 272) e das questões políticas em debate; e 6) desconfiança dos cidadãos nas instituições democráticas, o que implica menor engajamento político da população.

Além do mais, as decisões que envolvem políticas públicas não são tomadas apenas pelos representantes do povo ou pessoas indicadas por esses representantes, mas também pela burocracia formada, em regra, por funcionários de carreira não eleitos. Em relação à burocracia, pode-se exemplificar como problemas: 1) o fato de não possuírem índice de desempenho facilmente identificável (MERCURO e MEDEMA, 1999, p. 94); 2) pouca publicidade em relação à forma como são tomadas as decisões (MERCURO e MEDEMA, 1999, p. 94); 3) corpo de funcionários, em regra, insulados de controle democrático; e 4) o risco de burocratas e clientes formarem coalizões poderosas, consequentemente compondo um grupo de interesse capaz de efetuar decisões políticas (MERCURO e MEDEMA, 1999, p. 94). Embora a burocracia tenha existência fundamentada na sua capacidade técnica, isso não garante a responsividade desses funcionários aos interesses da população.

Portanto, considero que o fato de Executivo e Legislativo serem eleitos pelo povo e de o Executivo possuir uma burocracia com melhor conhecimento da relação entre a escassez de recursos e o conjunto das necessidades que esses recursos devem atender não parece suficiente para afirmar, sem maiores problemas, que a escolha da canalização de recursos 
públicos feita por esses poderes levará a uma formulação e gestão democráticas das políticas públicas em matéria de direito sociais.

Paulo Todescan Lessa Mattos defende a tese de que a década de 1990 foi um período de reconfiguração das relações entre os poderes Executivo, Legislativo e Judiciário e das relações entre Estado e sociedade civil. Houve uma valorização da sociedade civil e da esfera pública como elementos constitutivos da democracia e, assim, das condições de legitimidade de políticas públicas. Faz-se necessário, portanto, novas arenas decisórias em matéria de políticas públicas, não limitadas, porém conectadas, ao processo de barganha político-eleitoral característico do eixo de circulação dos poderes políticos (Administração Direta - Poder Legislativo) (MATTOS, 2005).

No próximo subitem, estudarei uma dessas novas arenas criadas para permitir maior participação nas políticas de saúde, os conselhos de saúde; e farei uma avaliação, com base na literatura que analisa sua atuação e os grupos que deles participam.

\section{Conselhos de Saúde e participação democrática}

No que tange especificamente às políticas de saúde, a Constituição Federal de 1988 atentou para a importância da participação democrática a ponto de colocá-la como um dos princípios sobre os quais se alicerça o sistema público de saúde. Além dos já citados princípios da universalidade, integralidade e equidade na saúde, está constitucionalizado também o princípio da participação da comunidade (art. 198, inc. III).

A Constituição optou por uma democracia que, além do sistema de representação por meio de eleições periódicas, busca ampliar-se por meio da criação de espaços onde a participação e a deliberação possam ocorrer mais efetivamente nas políticas de saúde. Os Conselhos de Saúde, criados pela Lei Federal 8.142/90, são espaços de deliberação e participação integrantes da própria “engenharia-político-institucional” (LABRA, 2005) do sistema público de saúde, que pretendem democratizar as decisões nesse setor por, idealmente, permitir que o cidadão comum, sem expertise e a um baixo custo, participe das decisões sobre políticas públicas de saúde (COELHO, 2007, p. 82).

Existem Conselhos em âmbito nacional, estadual e municipal, e a participação neles é dividida da seguinte maneira: 50\% entidades de usuários; 25\% entidades de trabalhadores 
da saúde; 25\% governo e prestadores de serviços conveniados. Em um levantamento de 2004, contabilizam-se mais de 5.500 Conselhos de Saúde no Brasil (COELHO, 2004, p. 255).

Com base na literatura que estuda os Conselhos de Saúde, procurarei refletir a respeito da capacidade desses conselhos de serem espaços de participação democrática complementares às eleições representativas, principalmente para os menos favorecidos.

Vera Coelho, em análise dos Conselhos de Saúde no município de São Paulo (2004, p. 258), aponta que a divulgação das eleições para os Conselhos são muito restritas e normalmente são informadas apenas às associações e aos movimentos populares conhecidos pelos gestores de saúde. Embora seja grande a participação de pessoas com baixa escolaridade e renda, acabam participando principalmente aqueles grupos que já possuem vínculos com atores estatais, o que a autora chama de “excluídos organizados”, preterindo aqueles que não possuem esses vínculos.

Outro problema apontado pela autora é a falta de recursos políticos dos Conselhos para vocalizarem suas demandas, o que lhes dá um papel ainda pouco relevante no processo político para definição da política de saúde (COELHO, 2004, p. 261-262). Posições do prefeito ou do secretário de saúde tendem a prevalecer sobre as dos Conselhos.

Em outro trabalho, a mesma pesquisadora apontou que o sucesso dos conselhos como espaço de participação dos menos favorecidos e em desempenhar um papel significativo na definição de políticas públicas depende da conjunção de fatores nem sempre presentes, como: 1) mobilização e organização da sociedade civil; 2) comprometimento das autoridades com projeto participativo; e 3) um desenho institucional aberto à participação mais plural (COELHO, 2007).

Maria Eliana Labra (2005, p. 371-372), com base nos relatórios finais da $11^{\mathrm{a}}$ e $12^{\mathrm{a}}$ Conferência Nacional de Saúde, aponta, entre outras coisas, para: 1) falta de representatividade dos conselheiros, muitas vezes indicados clientelisticamente; 2) pouca informação da população sobre os Conselhos, que acarreta baixa adesão e envolvimento da população; e 3) críticas aos secretários de saúde, que não discutem o orçamento, não prestam contas da execução da política aos conselheiros, não acatam as resoluções do colegiado, definem previamente ou manipulam a pauta de discussão, impõem decisões com 
fundamentos tecnocráticos, evitam discussões de teor político e cooptam conselheiros ou lideranças comunitárias com táticas clientelísticas.

Sem diminuir a importância dos conselhos de saúde, é importante frisar os seus limites atuais, quais sejam: 1) alta inclusão de grupos vinculados aos gestores públicos de saúde; 2) exclusão de grupos não organizados, o que atinge especialmente os usuários em geral, que possuem demandas difusas, ao contrário de portadores de patologias ou deficiências (LABRA, 2005, p. 374); 3) exclusão de grupos organizados sem vínculos políticos; 4) há dúvidas quanto à legitimidade da representação da sociedade civil no Conselho, uma vez que o processo de escolha dos representantes não é transparente; e 5) nem sempre o produto das deliberações nos conselhos é acatado pelos governantes, que podem usar diversos artifícios para controlar os outros conselheiros e não ter o Conselho contra a gestão pública.

No subitem seguinte, tentarei analisar se o Judiciário pode ser um espaço de participação complementar à democracia representativa e aos Conselhos de Saúde, de forma a compensar algumas das limitações que eles apresentam.

\section{Judiciário e participação democrática nas políticas públicas}

Nessa segunda seção, o objetivo é apontar que, embora a atuação do Judiciário apresente inúmeras dificuldades, esta não é uma característica exclusiva desse poder. Tanto a representação política quanto os foros específicos de participação e deliberação, ainda que muito importantes, possuem sérias limitações para a participação dos cidadãos, principalmente para aqueles menos favorecidos e organizados.

Pode-se considerar a hipótese de que é a debilidade das instituições de representação democrática e a deterioração dos espaços tradicionais de mediação política e social que transferem ao Poder Judiciário um papel mais ativo em matéria de direitos sociais (ABRAMOVICH, 2005, p. 204). Além do mais, a existência de um Estado com burocracias cada vez maiores e insuladas de controle democrático faz com que o controle sobre a Administração, pela linguagem de direitos por meio do poder Judiciário, seja cada vez mais atrativo (EPP, 1998, p. 16).

No presente item, procuro mostrar que, embora sejam válidas algumas críticas e reservas a respeito da judicialização da saúde, elas deixam de perceber que o Judiciário pode ter uma 
função importante dentro de um Estado Democrático, e sua participação eficiente do ponto de vista da cidadania civil e da accountability - no sentido de controle democrático de instituições políticas por meio da participação em processos decisórios de políticas públicas - pode significar uma ampliação democrática para além dos limites demarcados pela democracia representativa (ARANTES e KERCHE, 1999, p. 31), inclusive em matéria de políticas públicas e direitos sociais.

Nesse aspecto, o Judiciário pode ser um mecanismo importante para o debate público porque: 1) sua função permite que ele receba reclamações daqueles afetados por uma decisão política, inclusive aqueles menos favorecidos e marginalizados do processo político (GARGARELLA, 2006, p. 27); 2) tem poder de exigir justificativas da Administração para suas decisões, o que enriquece e legitima a discussão pública pela entrada de mais atores e novos pontos de vista; e 3) as ações judiciais podem indicar ao governo a necessidade de revisar algumas políticas e a forma como elas são implementadas (GAURI e BRINKS, 2008, p. 14).

Grupos menos favorecidos - cujos reclamos não são atendidos por seus representantes políticos e que não conseguem voz em outras instâncias de participação, ou, se conseguem, não logram sucesso em suas demandas - podem ter no Judiciário um importante canal institucional para expressar suas demandas ignoradas e colocar em debate as escolhas de prioridades previamente feitas (GARGARELLA, 2006, p. 27; CAPPELLETTI, 1999, p. 99; PIETERSE, 2008, p. 379).

Werneck Vianna e Marcelo Burgos, partindo de um conceito de “cidadania complexa” que não se limita ao “eixo especializado da representação política” e que proporciona outros cenários de participação na vida pública -, justificam o uso do Judiciário como um desses cenários que servem de "médium para a tradução de questões pertinentes à sociabilidade em pontos de agenda pública” (2002, p. 372). Eles, por meio de pesquisas empíricas, também apontam que o uso do Poder Judiciário, além da função de proteger direitos, tem o condão de ampliar e diversificar a participação da sociedade na construção de uma agenda pública (VIANNA e BURGOS, 2002, p. 484).

A transferência de algumas decisões relativas à proteção de direitos para o Judiciário pode ser bastante valiosa para os menos favorecidos. Esse argumento é bastante válido principalmente para países de grande desigualdade, como é o caso do Brasil, onde os 
tribunais podem responder às reclamações dos menos favorecidos, quando estes traduzem uma demanda social em jurídica, trazendo, assim, maior visibilidade para algumas reivindicações que seriam “sufocadas” em uma arena meramente política (VIEIRA, 2007, p. 49).

O Comitê dos Direitos Econômicos Sociais e Culturais da ONU, no seu Comentário Geral n. 9, expressa um entendimento semelhante ao afirmar que uma concepção de direitos econômicos, sociais e culturais que lhes nega a proteção pelos tribunais poderia reduzir drasticamente a capacidade do Judiciário de proteger os direitos dos grupos mais vulneráveis e menos favorecidos da sociedade (UNITED NATIONS, 1998).

Um trabalho de Paul Hunt (2007), que trata das doenças negligenciadas no mundo, aponta para a importância da atuação do poder Judiciário na defesa do direito à saúde dos menos favorecidos na sua luta pelo fornecimento de medicamentos para combatê-las. O conceito de “doenças negligenciadas” refere-se a enfermidades que atingem os mais pobres entre os pobres (the poorest of the poor) e que são também os que possuem menos poder na sociedade (powerless), além de serem marginalizados (HUNT, 2007, p. 3-4). As características dessa "população negligenciada" fazem com que sua voz dificilmente chegue às instâncias políticas de representação, o que torna o Judiciário uma instituição relevante para a proteção de seu direito à saúde.

Em algumas situações, mesmo que os pedidos feitos ao Judiciário não sejam atendidos, ainda assim pode haver efeitos indiretos positivos na judicialização de demandas sociais, por potencialmente constranger o poder público a firmar acordos fora do Judiciário e suscitar ou intensificar o debate público e criar movimento político em torno da questão (GLOPPEN, 2006, p. 42).

Além do mais, o Judiciário pode ser uma via relativamente barata ou até mesmo gratuita para o interessado, quando a ação é ajuizada pelo Ministério Público ou quando seu autor é representado por organizações não governamentais (ONGs) ou por defensores públicos.

Portanto, mais do que fechar discussões travadas em instâncias de democracia representativa, o Judiciário adiciona outra instância para o debate e deliberação também democráticos (BRINKS e GAURI, 2008, p. 343). 
Contudo, para que o Judiciário possa ser um espaço de participação para esses grupos, há que se discutir o acesso à Justiça no Brasil, pois suas deficiências explicam, em parte, o fato de que pessoas social e economicamente já favorecidas apareçam nas pesquisas empíricas já citadas como as principais beneficiárias da judicialização da saúde.

Epp (1998, p. 3, 45, 203) já apontou para o fato de que mudanças sociais por meio do poder Judiciário, o que ele chama de rights revolution, dependem necessariamente de significativa assistência legal e que, caso isso não seja disponível para os menos favorecidos, por meio de associações, advogados pro bono ou órgãos públicos, eles não atingirão a “agenda judicial”, e as ações judiciais tenderão a defender interesses dos já favorecidos.

No caso do Brasil, para avaliar as possibilidades de o Judiciário no Brasil ser uma voz institucional para os menos favorecidos demandarem a concretização de seu direito à saúde, é preciso olhar especialmente para duas instituições públicas que podem promover o acesso à Justiça entre elas: o Ministério Público e a Defensoria Pública. O desenvolvimento desse potencial do Judiciário depende de como atuam essas duas instituições, e isso tentarei avaliar na pesquisa empírica.

\section{Pesquisa empírica}

\section{Ministério Público}

O interesse pelo Ministério Público surge a partir de um trabalho de Lopes (2006, p. 221264) que, estudando e comparando Ações Civis Públicas que envolvem direito à saúde e educação em dois períodos - de 1989 a 1996 e 1996 a 2003 -, aponta para uma crescente preocupação do Ministério Público em buscar a tutela dos direitos à saúde e à educação das populações mais pobres, ao invés de defender interesses mais vinculados à saúde e educação da classe média.

As Ações Civis Públicas, que têm no Ministério Público seu principal patrocinador, possuem um grande caráter inovador na propagação da cidadania. Esta é a posição de Vianna e Burgos (2002, p. 466), para quem o maior uso das Ações Civis Públicas em matéria de políticas públicas significa que elas são crescentemente percebidas como lugar 
de afirmação de direitos em face do Poder Público por um grande espectro de atores sociais e políticos.

Contudo, essa percepção sobre o Ministério Público não é unânime. Hoffman e Bentes (2008, p. 111) apontam que o Ministério Público tende a patrocinar causas que repercutem na mídia, e como a atenção dos meios de comunicação é geralmente voltada para aqueles que conseguem vocalizar suas demandas de forma alta e eloquente, os quais, em regra, não são os menos favorecidos.

Lançar luz sobre essa discussão a respeito de quem são os beneficiários da atuação do Ministério Público no caso específico da tutela do direito à saúde é também uma grande motivação para essa pesquisa.

Ela foi feita junto à Promotoria da Saúde Pública (GAESP) do Ministério Público do Estado de São Paulo em janeiro de 2009. Além das Ações Civis Públicas propostas por essa promotoria, estudarei as formas de solução de conflito pré-judiciais, em que a questão se resolve sem necessidade de ação judicial, mas com a possibilidade de usá-la como poder de barganha na negociação com o Poder Público.

\section{Ações Civis Públicas}

De 1999 - quando é criada a Promotoria de Saúde Pública - até o ano de 2008, o GAESP promoveu um total de 62 Ações Civis Públicas (ACPs). Para fins deste trabalho foram analisadas apenas aquelas em que se tutelava o direito à saúde por meio da exigência de uma ação do Estado que implicasse gasto público, o que resultou em um total de 32 ACPs analisadas, metade do total, o que indica uma atuação do Ministério Público na defesa de interesses dos menos favorecidos. 


\section{Gráfico 1 - Ano de proposição}

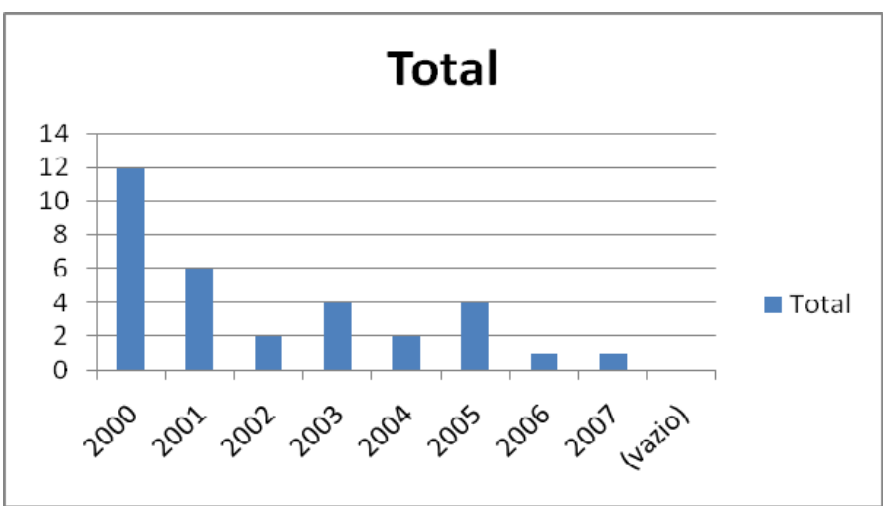

Percebe-se uma tendência de diminuição no número de ACPs propostas pela promotoria. A hipótese que levanto, e que será mais discutida posteriormente, é a de que a diminuição no número de ações propostas decorre de uma propensão maior das secretarias de saúde de tentar resolver a demanda em fase anterior à proposição da ação, talvez em decorrência de saber que a jurisprudência tende a não aceitar seus argumentos de defesa.

\section{Gráfico 2 - Tipo de pedido}

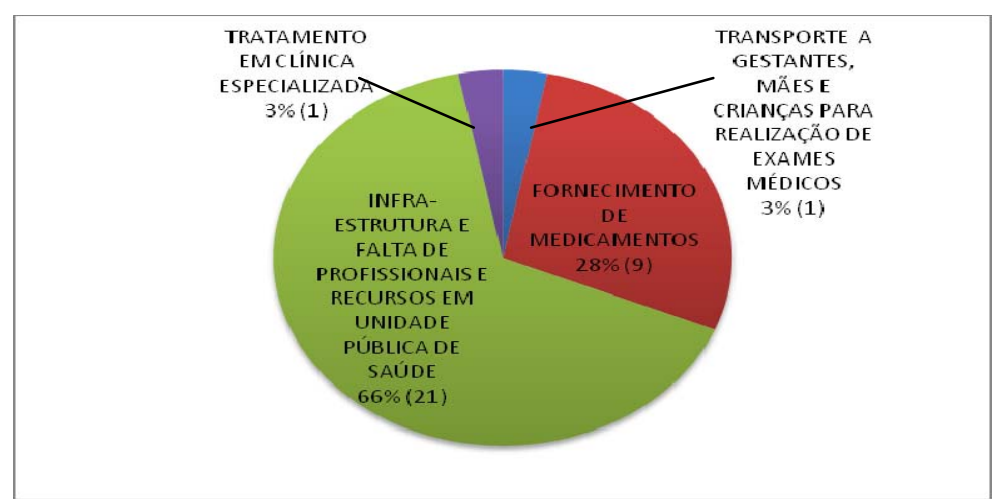

Como mostra o Gráfico 2, as ACPs do GAESP são voltadas principalmente para demandar o fornecimento de medicamentos e para solução de problemas de infraestrutura e falta de profissionais e recursos em unidade pública de saúde (o que inclui problemas com higiene; manutenção de prédio; falta de insumos hospitalares; equipamentos, ambulâncias, remédios e profissionais de saúde; adequação do hospital a normas técnicas de segurança e procedimento médico), em hospitais, pronto-socorros e unidades básicas de saúde. 
As ACPs em que se pede exclusivamente fornecimento de medicamentos são para as seguintes patologias: hepatite C (2 ACPs); hipertemia maligna; fibrose cística; doença renal crônica; epilepsia; doença pulmonar obstrutiva crônica; e adrenoleucodistrofia. Um outro caso refere-se à falta de medicamentos de alto custo no Hospital das Clínicas.

Das nove ações, em cinco houve concessão de liminar e em duas não. Nas outras, não há informações a esse respeito. Infelizmente, há pouca informação acerca das fases processuais posteriores à concessão da liminar, o que impede a avaliação do sucesso dessas ACPs no Judiciário.

Para aqueles medicamentos em que constava no processo o custo para seu fornecimento, percebe-se que, em regra, são medicamentos de alto custo. Para tratamento de adrenoleucodistrofia, pede-se o fornecimento de Óleo de Lorenzo, a um custo de R\$ 400 a caixa com seis frascos. Para tratamento de doença renal crônica, o medicamento Renagel custa R\$ 802,56 o frasco. O medicamento Dantroleno Sódico para hipertemia maligna tem o preço de R 2.845 um kit com três caixas. Por fim, para fibrose cística, o tratamento por paciente custa R \$ 8.000 mensais; e para hepatite C, o tratamento com Interferon Peguilado tem o valor de R 5.000 mensais.

Um dado que indica de maneira incisiva a atuação do MP na tutela dos direitos dos menos favorecidos é o predomínio de demandas que envolvem hospitais, pronto-socorros e unidades básicas de saúde do Poder Público ou a ele vinculados, que são utilizados principalmente pela população de mais baixa renda ("infraestrutura e falta de profissionais e recursos em unidade pública de saúde”). Ao contrário do fornecimento de medicamentos, especialmente os de alto custo, em que a renda não é uma variável tão relevante para o uso ou não desse serviço público, o sistema público hospitalar é usado principalmente por aqueles de mais baixa renda e que não possuem plano privado de saúde.

Com base nos nomes das unidades de saúde para as quais as ACPs demandam ação governamental, descobri os bairros em que se encontram, e fiz o levantamento do IDH do distrito ao qual pertence cada unidade, com base em dados da Prefeitura do Município de São Paulo (2002), que divide o IDH em baixo (abaixo de 0,5), médio e alto (acima de 0,8).

Dessa forma, descobre-se que dos 21 casos, em dez trata-se de unidades de saúde em distritos de baixo IDH, em dez de médio IDH e há um caso de hospital em distrito de alto 
IDH. O equilíbrio entre distritos de baixo e médio IDH é um dado que será constatado também nas ações propostas pela Defensoria Pública.

O fato de que metade das unidades de saúde, para as quais se pede melhor infraestrutura e recursos materiais e humanos, encontram-se nas regiões mais pobres da cidade, em que o índice de IDH é considerado baixo, mostra que algumas demandas da periferia, os mais carentes entre os carentes, conseguem chegar ao Ministério Público e, dessa forma, passam a fazer parte das preocupações dos gestores públicos.

O que chama a atenção é que nove das unidades de saúde para as quais se pede melhores condições (90\% entre aqueles de baixo IDH) localizam-se na Zona Leste da cidade (Sapopemba, Itaquera e Guaianazes). Levanto a hipótese de que isso talvez possa ser explicado pela existência de um forte movimento social de saúde nessa região, organizado desde 1970, ligado ao movimento sanitarista e atuante até hoje, ${ }^{3}$ o que sugere um diálogo, digno de futuras pesquisas, entre o Ministério Público e esse movimento social.

A percepção de que o MP tende a patrocinar causas daqueles que conseguem dar visibilidade às suas demandas (HOFFMAN e BENTES, 2008, p. 111) tem algum lastro na realidade das ACPs e dos inquéritos civis pesquisados. Boa parte das unidades de saúde para as quais se pede melhora nas condições encontra-se em regiões de IDH médio, onde vive a classe média, e mesmo em regiões de IDH alto. Seguramente, não é nessas áreas que as condições de hospitais, pronto-socorros e UBSs são piores. O que essa percepção não considera é que, de acordo com minha hipótese, quando os menos favorecidos nas periferias conseguem organizar-se, suas demandas passam a ser ouvidas também, como é o caso das unidades de saúde na zona leste de São Paulo.

Quanto ao sucesso dessas ações, nos processos em que constava essa informação (13), em nove casos o juiz deu ganho de causa ao Ministério Público, obrigando o Estado a efetivar as mudanças reclamadas, e em quatro o pedido não foi concedido.

\footnotetext{
${ }^{3}$ Sobre o movimento de saúde na Zona Leste ver: http://www.movimentosaude.org/index.php.
} 
Inquéritos civis públicos arquivados

Outro dado interessante e cuja pesquisa foi possível é em relação aos inquéritos civis públicos arquivados sem proposição da Ação Civil Pública. ${ }^{4}$ Esse dado ajuda a refletir a respeito da percepção de que muitos dos casos conseguem ser resolvidos em uma fase préjudicial.

Os registros desses inquéritos civis públicos arquivados ficam guardados no MP Estadual por três anos. Por isso, pudemos apenas pesquisar dados a partir de 2006. Em 2006, 2007 e 2008, houve um total de 66 arquivamentos; destes, 35 envolviam pedidos contra o Poder Público no sentido de envolver alguma prestação positiva. Os outros 31 não entraram na análise por fugirem do escopo do trabalho.

\section{Gráfico 3 - Número de inquéritos civis públicos com pedidos contra o poder público arquivados}

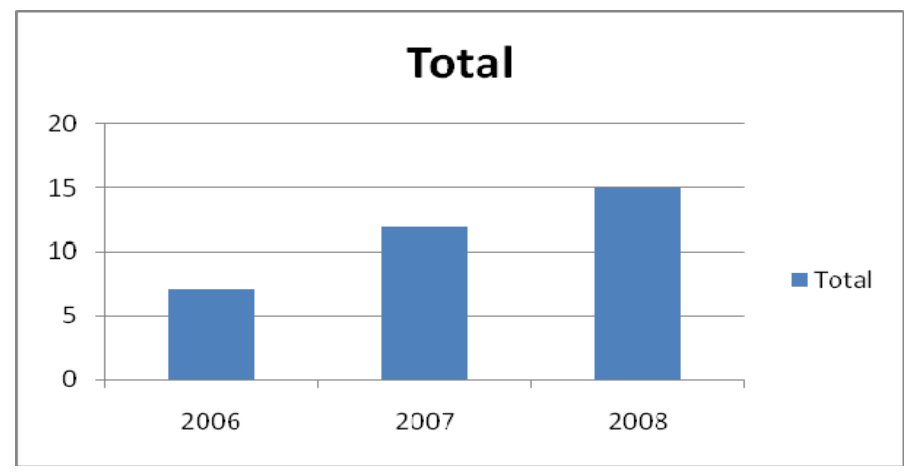

O Gráfico 3 aponta para uma tendência crescente no número de inquéritos civis públicos arquivados sem proposição da ação. Embora a margem temporal de três anos não permita afirmações peremptórias, pode-se sugerir que há uma tendência em se aumentar o número de casos resolvidos pré-judicialmente, o que contrasta com a diminuição no número de Ações Civis Públicas propostas. Em 2008, por exemplo, não houve registro de proposição de ACPs, ao mesmo tempo em que foi significativo o número de arquivamentos. A inexistência de dados anteriores a 2006 impede conhecer de forma mais precisa se existe

\footnotetext{
${ }^{4} \mathrm{O}$ inquérito civil público é uma fase administrativa prevista na Lei 7.345/85 (Ações Civis Públicas), conduzida pelo Ministério Público para apuração e investigação dos fatos, e que deve anteceder o ajuizamento de uma ação civil pública. O ajuizamento não ocorre quando se consegue um acordo entre as partes, ou quando não houver provas suficientes para fundamentar uma ação. Nesses casos, há o arquivamento do inquérito civil público.
} 
uma relação entre ACPs propostas e inquéritos civis arquivados, mas os poucos dados existentes sugerem que ela é inversamente proporcional.

Dos casos analisados, novamente os que apareciam em maior quantidade eram aqueles relacionados às irregularidades em unidades de saúde (infraestrutura, atraso em atendimento, falta de profissionais e materiais), que correspondem a 11 casos; e aqueles envolvendo fornecimento de medicamentos e vacinas, que representam nove casos.

Sobre a localização das unidades de saúde, percebemos a seguinte divisão com base no IDH dos distritos onde se encontram:

\section{Gráfico 4 - Índice de Desenvolvimento Humano}

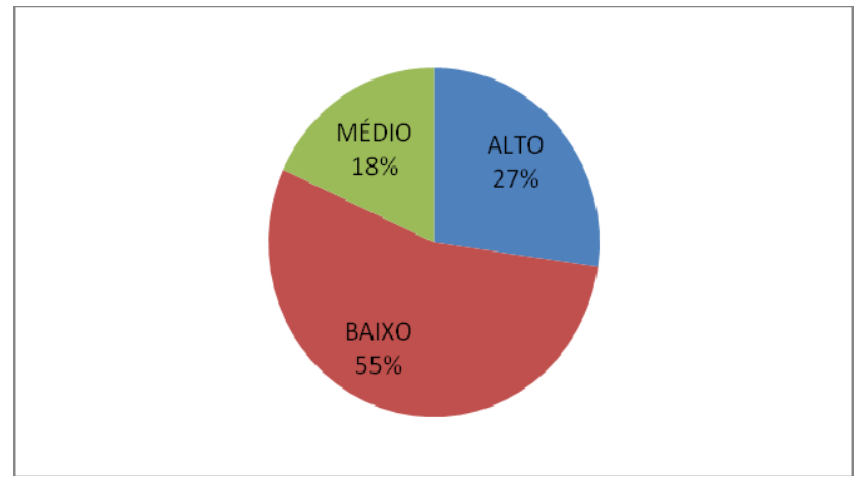

Dentre os de baixo IDH, cinco dos seis localizam-se na zona leste, o que aponta que os dados analisados no item anterior não são produtos do acaso, mas alguma relação deve guardar com o fato de essa região ter movimentos de saúde consolidados e atuantes.

Para saber até que ponto o grande número de arquivamentos é decorrência da propensão do Executivo a corrigir sua eventual falha ou omissão sem necessidade de uma ação judicial, mas com a sua ameaça iminente, é preciso saber a razão pela qual houve o arquivamento. O Gráfico 5 mostra que, de fato, a administração busca cumprir aquilo que lhe está sendo demandado, seja imediatamente, gradualmente ou oferecendo um plano para o cumprimento. 


\section{Gráfico 5 - Razão para arquivamento do inquérito civil público}

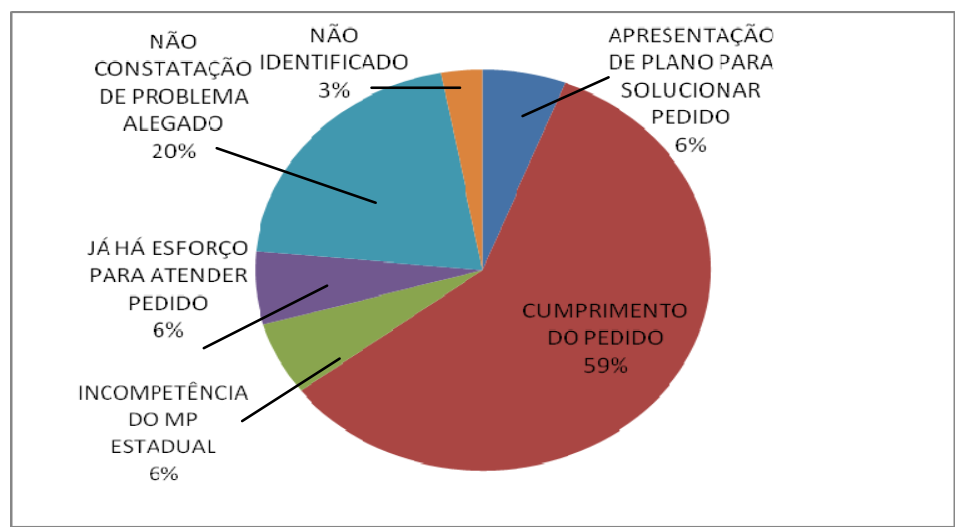

\section{Defensoria Pública}

A Defensoria Pública é a instituição responsável por prestar assistência jurídica gratuita aos cidadãos de baixa renda que não possuem recursos financeiros suficientes para contratar um advogado particular. No Estado de São Paulo, a Defensoria foi criada pela Lei Complementar 988 de 2006, mas sua função já era realizada anteriormente pela Procuradoria de Assistência Judiciária, ligada à Procuradoria Geral do Estado. Ela atende pessoas cuja renda familiar não ultrapasse três salários mínimos. ${ }^{5}$

Luciana Cunha (2001, p. 201) entende que é a Defensoria Pública a instituição capaz de transformar as demandas das camadas mais pobres da população em realização de direitos, inserindo-as no cenário político e jurídico.

Algumas pesquisas já apontam para o papel relevante da Defensoria Pública em matéria de direito à saúde. Terrazas (2008) identificou que uma parte das ações era de pessoas que gozavam de assistência jurídica gratuita. Ana Maria Messeder (2005) traz dados ainda mais incisivos sobre a atuação da Defensoria Pública, ao mostrar que, entre 1991 e 2002, ela patrocinou mais da metade das ações envolvendo pedidos de medicamentos.

A partir desses trabalhos, faço a leitura de que, embora o problema do acesso à justiça seja grave no Brasil, o estudo das ações da Defensoria Pública pode já indicar a importância da

\footnotetext{
${ }^{5}$ Em casos excepcionais, algumas pessoas cuja renda familiar ultrapasse esse teto estabelecido podem ser assistidas, dependendo da avaliação no atendimento pelo Defensor Público.
} 
proteção jurisdicional do direito à saúde para os menos favorecidos, que teriam demandas legítimas e cujo impacto no orçamento público não é tão significativo.

Além de analisar as ações judiciais propostas pela Defensoria Pública, estudarei também os resultados da parceria entre a Defensoria e a Secretaria Estadual de Saúde, pois é um ótimo exemplo de efeito indireto da judicialização da saúde e da possibilidade de diálogo e aproximação entre as instituições. Ademais, de acordo com os próprios Defensores, essa parceria tem diminuído o volume de ações em enorme proporção.

Estudo das ações judiciais

As ações que envolvem pedido de bens e serviços de saúde patrocinados pela Defensoria Pública são concentradas na “Unidade Fazenda Pública”. Nesta unidade, as ações são divididas entre cinco bancas, tendo cada banca um(a) defensor(a) responsável.

As ações são distribuídas pelo critério de ordem de chegada, o que faz com que todas as bancas tenham um número praticamente igual de processos e que a distribuição por temas seja muito semelhante. Em virtude da enorme quantidade de processos, aleatoriamente optei por analisar apenas uma das bancas, a terceira, por entender que ela, assim como qualquer outra banca, é uma amostra representativa de 20\% aleatoriamente construída.

Também foi necessário um corte temporal e fez-se a opção por analisar apenas as ações a partir de 2006, ano em que a Defensoria Pública começa a funcionar, dando continuidade ao trabalho da Procuradoria de Assistência Judiciária. A pesquisa encerrou-se ao final de fevereiro de 2009.

Resultados

Chama a atenção a variedade de patologias de que sofrem os representados pela Defensoria Pública. Nos 340 processos analisados, foram registradas 156 doenças, que apareceram 511 vezes no total. ${ }^{6}$ As mais frequentes são diabetes $(25,24 \%)$, paralisia cerebral $(6,65 \%)$,

\footnotetext{
${ }^{6}$ Em diversos casos, um paciente sofre de mais de uma doença, logo a frequência de doenças não corresponde ao número de processos analisados.
} 
hipertensão arterial (5,48\%), glaucoma (3,32\%), acidente vascular cerebral (3,33\%), cardiopatias (3,33\%), neoplasias (2,35\%), que, somadas, não alcançam 50\% do total.

Os pedidos mais frequentes são de insumos para controle de diabete (insulinas, aparelhos para aferição de glicose, lancetas, fitas reagentes, agulhas e seringas) e fraldas descartáveis para portadores de paralisia cerebral e para aqueles que sofreram acidente vascular cerebral. Em alguns processos, consta o custo do medicamento ou tratamento médico pedido. Os dados fornecidos, em razão do tipo de pedido, não aparecem de forma uniforme, ora aparecendo o preço por unidade ou totalidade do tratamento, ora o custo dos medicamentos ou tratamentos de que o paciente necessita calculado por determinado período de tempo. Portanto, esses dois tipos de dados foram analisados separadamente.

Dentre os 78 casos em que o custo é apresentado para dado período de tempo, por aparecerem calculados em anos ou meses, foi possível uniformizar as ocorrências e descobrir o seu custo mensal. A mediana dos custos mensais é de R\$ 289,92. O gráfico de dispersão mostra que, salvo poucas exceções, não se trata de pedidos de altíssimo custo.

\section{Gráfico 6 - Custo mensal de medicamentos e tratamentos médicos}

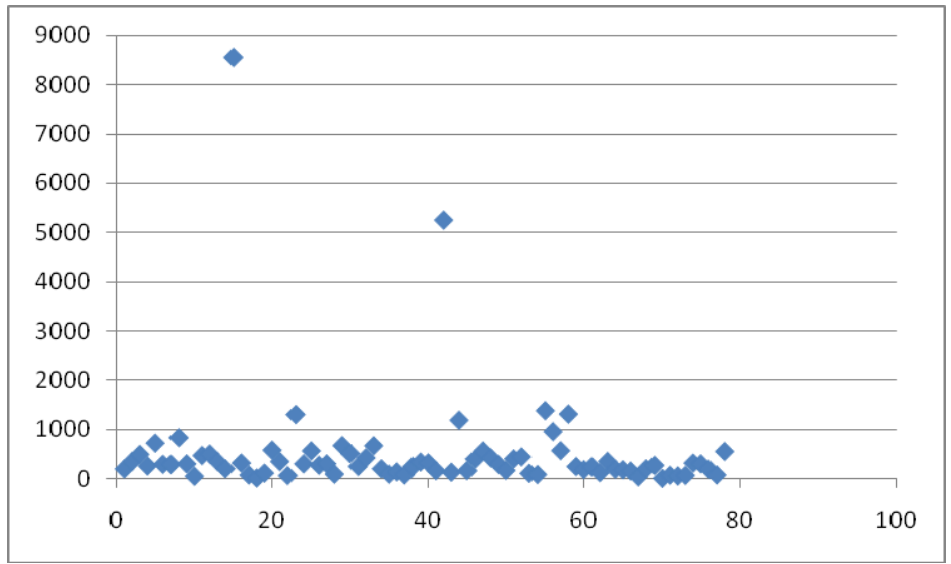

No eixo Y estão os valores em reais

No eixo X os números referem-se apenas à ordem aleatória em que foi tabulado cada um dos 78 casos.

Em alguns poucos casos, total de 14, consta o custo total para tratamento ou controle da patologia de que sofre o assistido pela Defensoria Pública, mas sem especificar o período que ele durará. São nesses casos que aparecem os pedidos com os custos mais elevados, de medicamentos para combate a neoplasias. Três pedidos chamam a atenção pelo seu custo 
elevadíssimo: um tratamento de bioquimeoterapia ao custo de R\$ 225.000 e dois medicamentos ao custo de R\$ 13.000 e R\$ 78.300.

Com relação ao sucesso das ações propostas pela Defensoria Pública, em 84,64\% foi concedida a liminar em favor do assistido, considerando os 293 casos em que consta informação a respeito da decisão judicial em sede de antecipação de tutela, e em apenas 3,75\% desses casos a liminar concedida não foi mantida na decisão de mérito. Os dados relativos ao resultado das ações em instâncias superiores mostram que quando a Defensoria perde em primeira instância (em sede de liminar ou em decisão final), ela consegue reverter a decisão em $77,78 \%^{7}$ dos casos na segundo instância. Já nos recursos interpostos pela Fazenda Pública contra decisão que concede medicamento ou tratamento médico, em $85,71 \%^{8}$ dos casos nega-se provimento para manter a decisão do tribunal a quo.

Percebe-se também que houve uma forte redução de casos envolvendo pedidos de medicamentos e tratamentos médicos na Defensoria de 2007 a 2008, muito provavelmente em razão do convênio celebrado entre a Defensoria Pública de São Paulo e a Secretaria Estadual de Saúde para que demandas, envolvendo direito à saúde, possam ser resolvidas antes que se chegue à fase judicial. A redução de 2007 a 2008 foi de 75,6\% e até fevereiro de 2009, a banca três teve apenas uma ação para esse tipo de pedido.

\section{Gráfico 7 - Ano de distribuição do caso para proposição de ação judicial}

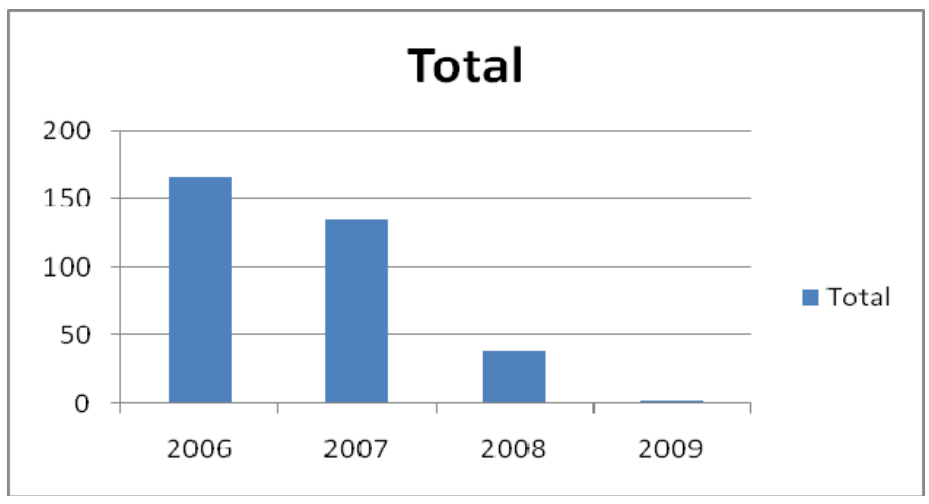

\footnotetext{
${ }^{7}$ Esse dado é obtido a partir dos 27 casos em que a informação a respeito do julgamento do recurso encontra-se disponível nos arquivos da Defensoria Pública.

${ }^{8}$ Esse dado é obtido a partir dos 63 casos em que a informação a respeito do julgamento do recurso encontra-se disponível nos arquivos da Defensoria Pública.
} 
Com relação à condição socioeconômica das pessoas representadas pela Defensoria Pública, o simples fato de a renda ser um critério para ser atendido por essa instituição já permitiria afirmar que se trata de pessoas socialmente não favorecidas. Porém, há um dado muito interessante que consta nos processos: a renda familiar das pessoas assistidas.

A renda familiar média é de $\mathrm{R} \$ 578,60 .{ }^{9}$ Contudo, este é um dado que não representa a realidade com precisão, pois é um universo amostral com desvio padrão muito alto, de R\$ 342,70. Nesses casos, a mediana é recomendável, pois tende a representar mais equilibradamente os valores extremos (LEVIN e FOX, 2004, p. 90). A mediana calculada é de $\mathrm{R} \$ 450$, o que significa que pelo menos metade dos assistidos pela Defensoria Pública em matéria de direito à saúde possuem renda familiar inferior ao valor do salário mínimo nacional estabelecido em fevereiro de 2009, cujo valor é de R\$ 465 (Medida Provisória nº 456/2009, de 30.01.2009).

Um dado disponível e que merece detalhamento é o IDH dos distritos onde moram as pessoas assistidas pela Defensoria Pública, que estão distribuídos no Gráfico 8: ${ }^{10}$

\section{Gráfico 8 - Índice de Desenvolvimento Humano}

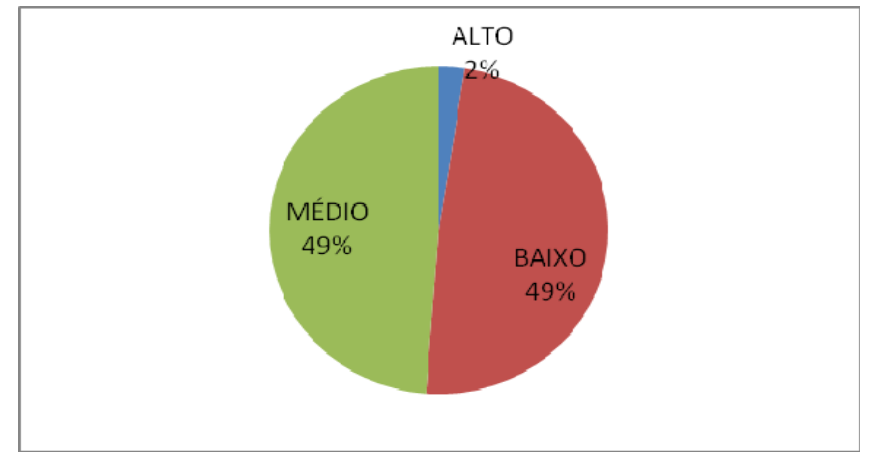

O equilíbrio entre distritos de IDH baixo e médio encontrado permite concluir que ela é uma instituição acessível a pessoas que residem nas áreas menos favorecidas da cidade (IDH baixo), ou seja, a periferia chega à Defensoria. A presença de distritos de IDH médio pode ser explicada pelo fato de essas pessoas viverem em áreas de maior visibilidade e

\footnotetext{
${ }^{9}$ Importante reconhecer que não houve correção dos valores com relação à inflação do período de 2006 a 2009, portanto, os números são aproximativos e não exatos.

${ }^{10}$ Foram incluídos nessa estatística apenas os assistidos com domicílio em São Paulo.
} 
onde há mais acesso à informação, mas isso não significa que sejam economicamente favorecidas, pois possuem renda baixa e não muito superior àquela dos residentes em distritos de maior exclusão social.

A comparação da renda das pessoas de acordo com o IDH da área onde residem mostra que de fato há uma diferença de renda que varia conforme o lugar onde se mora. Embora os moradores de áreas de IDH médio apresentem uma renda familiar melhor que aqueles que vivem em áreas de baixo IDH, percebe-se que continuam sendo pessoas cuja renda familiar não é alta.

Quadro 1 - Renda das pessoas de acordo com o IDH da área onde residem

\begin{tabular}{|l|l|l|l|}
\hline IDH & MÉDIA & $\begin{array}{l}\text { DESVIO } \\
\text { PADRÃO }\end{array}$ & MEDIANA \\
\hline BAIXO & $\mathrm{R} \$ 551,31$ & $\mathrm{R} \$ 343,90$ & $\mathrm{R} \$ 408$ \\
\hline MÉDIO & $\mathrm{R} \$ 601,40$ & $\mathrm{R} \$ 342,10$ & $\mathrm{R} \$ 518$ \\
\hline ALTO & $\mathrm{R} \$ 820,20$ & $\mathrm{R} \$ 367,30$ & $\mathrm{R} \$ 830$ \\
\hline
\end{tabular}

No estudo do MP Estadual, identificou-se, entre os distritos de baixo IDH, uma enorme concentração de ações civis públicas para tutelar o direito à saúde da população que vive na Zona Leste de São Paulo, região onde movimentos sociais da área de saúde pública são muito ativos. Testaremos se isso se aplica para casos individuais na Defensoria Pública. Dentre os distritos de baixo IDH encontramos a seguinte divisão:

\section{Gráfico 9 - Distribuição dos distritos de baixo IDH por zona}

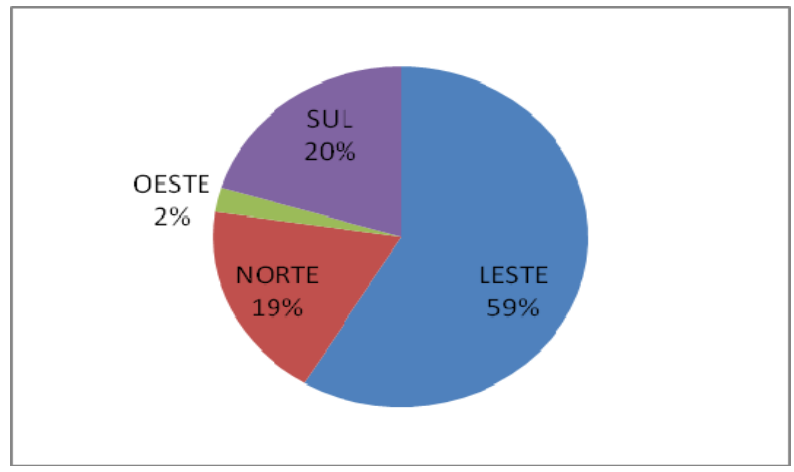


Embora com uma distribuição mais dispersa se comparada com a análise das ACPs propostas pelo MP Estadual, percebe-se a prevalência de pessoas residentes na Zona Leste da cidade (quase 60\%). Novamente, rejeito que essa desproporção seja produto de coincidência e levanto a hipótese de que um movimento de saúde historicamente atuante na Zona Leste da cidade também influencia os indivíduos a buscarem por meio da Defensoria a tutela de seu direito á saúde.

Contudo, o fato de haver maior heterogeneidade, se comparada com o MP, em relação ao lugar de onde vêm as demandas indica que a Defensoria pode ter um papel muito mais relevante para canalizar aquelas demandas mais dispersas e dos grupos menos organizados, permitindo o acesso destes ao Judiciário.

Em termos de promoção do acesso à Justiça para os grupos mais excluídos, a Defensoria exerce um papel fundamental na ampliação da sua participação, embora os efeitos de suas ações limitem-se tão-somente aos indivíduos que tiveram um pedido concedido e o uso de liminares, embora eficientes, trazem menor espaço para diálogos dentro de cada processo judicial.

Estudo da parceria entre Defensoria Pública e Secretaria Estadual de Saúde

Em 11 de março de 2008, foi inaugurada uma parceria entre a Defensoria Pública e a Secretaria Estadual de Saúde para regularização de fornecimento de bens e serviços relacionados à saúde sem necessidade de ações judiciais para tanto.

Dessa forma, a pessoa que busca a Defensoria por não ter tido acesso a um bem ou serviço de saúde por parte do poder público é encaminhada, primeiramente, ao Plantão da Secretaria de Saúde instalado na própria Defensoria Pública, onde funcionários da Secretaria analisam o pedido e, quando entendem que esse deve ser atendido, já encaminham a pessoa para uma unidade do serviço público onde poderá receber o bem ou serviço demandado.

Nesses casos, dá-se um prazo de 40 dias para que a pessoa comece a receber o bem ou serviço que a Secretaria de Saúde comprometeu-se a fornecer e, somente em caso de descumprimento, a Defensoria instaura a ação judicial, pleiteando em juízo em favor da pessoa cujo pedido não foi atendido. 
A Defensora Vânia Agnelli Sabin Casal aponta as seguintes vantagens dessa parceria entre as duas instituições: os cidadãos conseguem ter o pedido atendido de forma muito mais rápida do que conseguiriam pela via judicial; aumento do diálogo entre a Defensoria e a Secretaria, e esse contato mais constante soluciona diversos problemas relacionados ao serviço público de saúde; diminui o volume de trabalho da Defensoria, antes sobrecarregada com esse tipo de ação.

Para se ter uma ideia de a efetividade dessa parceria, cabe olhar para a diminuição do número de ações judiciais propostas pela Defensoria Pública envolvendo direito à saúde. De acordo com dados da própria instituição, antes da existência dessa parceria, havia uma média de 150 a 180 ações por mês e, desde então até fevereiro de 2009, a média havia baixado para 16 a 20 ações por mês.

\section{Resultados}

Há dados referentes aos atendimentos pelo Plantão da Secretaria de Saúde na Defensoria desde junho de 2008. Considerando os registros de atendimento de junho de 2008 até janeiro de 2009 que tivessem informações completas sobre o objeto do pedido e o resultado do atendimento, contei um total de 715.

Para garantir a aleatoriedade da amostra, utilizei o método da amostragem sistemática: os registros foram ordenados pela data, organizados em grupos de cinco e apenas o primeiro de cada grupo entraria na análise. Dessa forma, cheguei a uma amostra de 148 registros. Essa amostra garante uma margem de erro de 7,3\%, que considero suficiente para os fins desta pesquisa.

Poucos dados constam dos registros dos atendimentos. Em relação ao mês em que foi feito o pedido, temos: 


\section{Gráfico 10 - Mês de atendimento}

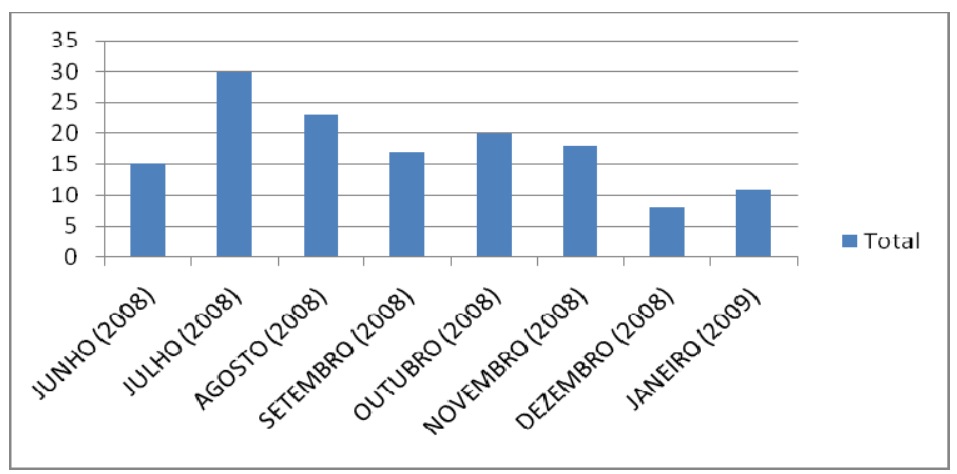

Já com relação ao objeto pedido, percebe-se que há uma grande variedade. No total, existem 148 objetos diferentes sendo pedidos (cabe lembrar que uma pessoa pode pedir mais de um objeto), que vai desde aspirinas até cirurgias e cadeiras de rodas. Pode-se destacar principalmente dois objetos, os únicos que possuem porcentagem maior que $5 \%$ do total: fraldas $(6,45 \%)$ e insulinas (21,15\%).

Para medir o sucesso desse plantão, observo o resultado do pedido, que pode ser: (1) atendimento do pedido pela Secretaria de Saúde, casos em que na ficha de atendimento está marcada a seguinte informação "recebi encaminhamento administrativo emitido pela secretaria de saúde para atendimento do pedido constante de receita médica”; (2) recusa do pedido pela Secretaria, informação que constará na ficha como "houve recusa ou impossibilidade de fornecimento (hipótese em que deverá ser encaminhado para ajuizamento de ação)”.

\section{Gráfico 11 - Resultado dos pedidos}

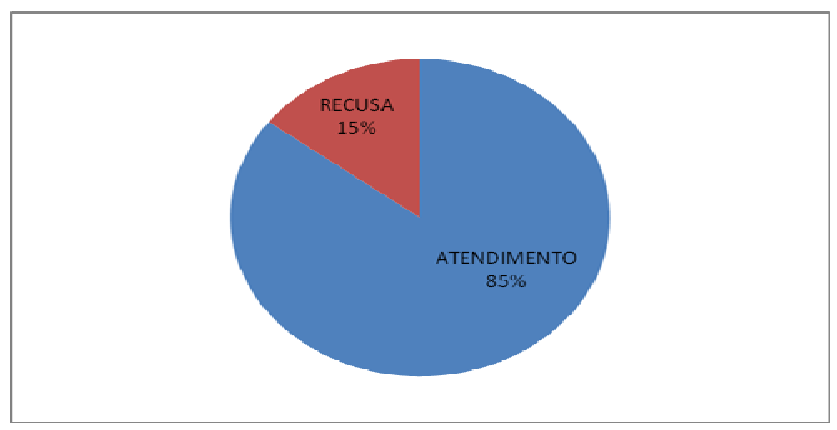


Percebe-se que na imensa maioria dos casos, a Secretaria de Saúde comprometeu-se a fornecer o bem ou serviço de saúde já na fase do atendimento no plantão, portanto, sem necessidade de se entrar com uma ação judicial. As porcentagens apontadas no Gráfico 11 são equivalentes à redução na quantidade de ações judiciais promovidas pela Defensoria em matéria de direito à saúde.

As recusas, total de 21, são, em grande parte, para pedidos de insulina e fraldas. Contudo, há casos em que esses dois objetos tiveram seus pedidos atendidos pela Secretaria.

Um questionamento que se pode fazer é a efetividade de se ter um pedido atendido pela Secretaria nesse plantão produto de parceria com a Defensoria. Ainda que a pessoa saia com um ofício, para que seu pedido seja atendido, nada garante que de fato haja a entrega do objeto, caso em que o paciente volta à Defensoria para a proposição da ação. Embora este seja um dado difícil de levantar, pela grande diminuição no número de ações propostas pela Defensoria, pode-se pressupor que, até agora, de fato a grande maioria dos pacientes conseguiu ter seu problema resolvido, do contrário haveria um incremento no número de ações em níveis semelhantes àqueles que existiam antes da parceria entre as duas instituições.

\section{Conclusões}

É preciso olhar realisticamente para o funcionamento de todas as instituições para se repensar a crítica de que o Judiciário acaba beneficiando os já favorecidos. Conforme sustenta Oliver (2006), as políticas de saúde (ou sua ausência) têm como elemento intrínseco o conflito e a disputa de interesses, e isso se manifesta entre membros do Executivo, no parlamento, na comunidade científica, na imprensa e em qualquer outra instância de tomada de decisão. Logo, grupos com maior força política, econômica e visibilidade conseguem defender melhor suas preferências. Isso não é exclusividade do poder Judiciário e do processo de adjudicação.

Portanto, a questão não é se os juízes devem ter alguma participação ou não nas políticas de saúde, em razão de serem os tribunais espaços utilizados pelos mais favorecidos e organizados, porque se a resposta for negativa, esse "não" teria que valer para as demais instituições de participação e, em última instância, para a própria democracia. Esse argumento, levado até suas últimas consequências, colocaria em questão a tutela de 
qualquer direito pelo Judiciário, como o devido processo legal, liberdade de expressão etc., já que também estes são mais bem protegidos para os mais favorecidos.

Como colocam Varun Gauri e Daniel Brinks (2008, p. 22),

Remover as cortes do processo decisório de políticas públicas (...) não é garantia de que legisladores e burocratas irão, subitamente, fazer políticas públicas brilhantes ou buscar o maior bem para o maior número de pessoas (...) nem que haja espontânea empatia com os pobres e marginalizados pelos burocratas, legisladores e prestadores privados de serviços.

Um dos pressupostos que tento defender nesse artigo é que no Judiciário os interesses dos menos favorecidos e organizados podem se manifestar de forma mais fácil, e esta é uma vantagem comparativa dessa instituição em relação às outras.

Mas o Judiciário só consegue exercer essa tarefa se houver a intermediação de outras instituições ou organizações capazes de apoiar os grupos mais marginalizados, ajudando-os a transformar suas necessidades em demandas jurídicas e, eventualmente, em agenda de políticas. Caso contrário, será esperável que os mais favorecidos sejam os que mais utilizam o Judiciário para defender seus interesses. Métodos participativos, quaisquer que sejam, não são automaticamente inclusivos, eles podem refletir ou aumentar divisões sociais preexistentes na comunidade (GEORGE, 2003, p. 10).

Em minha pesquisa empírica, fica claro que as demandas dos menos favorecidos, inclusive nas periferias, possuem acolhida no Ministério Público e na Defensoria Pública. Pode-se dizer que a judicialização da saúde, em alguma medida, promove a participação de uma parcela (pequena, se pensarmos nos problemas de acesso à Justiça e na quantidade de falhas nos serviços de saúde) dos menos favorecidos nas políticas públicas de saúde.

Contudo, isso não significa que todos os problemas distributivos relacionados à judicialização da saúde estariam resolvidos com uma atuação maior da Defensoria Pública e do Ministério Público na tutela dos direitos dos menos favorecidos.

Este trabalho trouxe alguma contribuição ao descrever uma parcela daqueles menos favorecidos que conseguem ter algumas demandas em matéria de saúde atendidas por meio do poder Judiciário, que é um aspecto da questão. O outro aspecto, e que precisa ser 
urgentemente pesquisado, é quem perde com essas decisões judiciais. Em um cenário de escassez de recursos, para se cumprir as decisões judiciais, quem quer que se beneficie delas, seguramente algum outro gasto teve que deixar de ser realizado e saber isso é de fundamental importância para esse debate.

O Secretário de Saúde de São Paulo afirmou que precisa cortar despesas com programas de atenção básica de saúde, como o Programa Saúde da Família, para cumprir os mandados judiciais (Estado de S. Paulo, 05.02.2005). A mesma afirmação ouvi de uma gestora de saúde em um debate a respeito do tema no X Congresso Paulista de Saúde Pública.

É difícil saber até que ponto isso é generalizável, mas intuo que isso seja possivelmente verdade. Se a participação política, conforme vimos, é importante para que um grupo social tenha políticas públicas que lhe favoreçam, é razoável pensar que os grupos com menos força política sejam os que menos têm condições de evitar que investimentos em políticas de seu interesse sejam cortados em um cenário em que o gestor é obrigado pelo Judiciário a realizar determinado gasto. Nesse caso, não me surpreenderia se houvesse um corte em políticas voltadas para a atenção básica de saúde das populações menos favorecidas economicamente e menos organizadas politicamente.

Também não se pretende colocar todas as expectativas no Judiciário nem defender que ele seja capaz de resolver todos os problemas da saúde no Brasil. Gerald Rosenberg (1993), embora falando de outra realidade e de outros direitos, já mostrou que colocar muitas expectativas de grandes mudanças sociais na litigância judicial pode ser decepcionante. A melhora da saúde pública no Brasil é uma tarefa complexa para a qual a participação democrática é apenas um elemento importante a ser considerado, e o Judiciário é apenas um entre diversos outros espaços onde essa participação pode ocorrer. Quero apenas defender que o Judiciário tem um papel a cumprir para uma concretização mais justa do direito à saúde.

\section{Referências}

ABRAMOVICH, V. Linhas de trabalho em direitos econômicos, sociais e culturais: instrumentos e aliados. Revista Internacional de Direitos Humanos, v. 2, n. 2, p. 204, 2005.

AMARAL, G. Direito, escassez e escolha. São Paulo: Renovar, 2001. 
ARANTES, R. B.; KERCHE, F. Judiciário e democracia no Brasil. Novos Estudos CEBRAP, n. 54, p. 31, 1999.

BRASIL. Constituição da República Federativa do Brasil. Brasília: Senado, 1988.

BRASIL. Ministério da Saúde. Determinação e avaliação do custo do Programa de Saúde da Família - PSF. Consórcio FGV-EPOS, 2001.

BUCCI, M. P. D. Políticas públicas e direito administrativo. Revista de Informação Legislativa, v. 34, n. 133, 1997.

CAPPELLETTI, M. Juízes legisladores? Porto Alegre: Sergio Antonio Fabris, 1999.

CANOTILHO, J. J. G. Constituição dirigente e vinculação do legislador: contribuição para compreensão das normas constitucionais programáticas. Coimbra: Coimbra Editora, 1983.

COELHO, V. S. P. Conselhos de Saúde enquanto instituições políticas: o que está faltando? In: COELHO, V. S. P.; NOBRE, M. (Orgs.) Participação e deliberação: teoria democrática e experiências institucionais no Brasil contemporâneo. São Paulo: Editora 34, 2004.

COELHO, V. S. P. Democratização dos Conselhos de Saúde: o paradoxo de atrair não aliados. Novos Estudos CEBRAP, n. 78, p. 77-92, 2007.

COLLUCI, C. Ações para obter remédios registram primeira queda em SP. Folha de S.Paulo, São Paulo, C9, 19.02.2009.

COLLUCI, C. Triplicam as ações judiciais para obter medicamentos. Folha de S.Paulo, São Paulo, C9, 09.01.2009.

CSDH. Closing the gap in a generation: health equity through action on the social determinants of health. Final report of the Comission on Social Determinants of Health. Geneva: World Health Organization, 2008.

CUNHA, L. G. S. Acesso à justiça e assistência jurídica em São Paulo. In: SADEK, M. T. (Org.) Acesso à Justiça. São Paulo: Fundação Konrad Adenauer, 2001.

EPP, C. The rights revolution: lawyers, activists and Supreme Court in comparative perspective. Chicago: University of Chicago Press, 1998.

ESTADO de S. Paulo, São Paulo, A22, 05.02.2005.

FERRAZ, M. B. Dilemas e escolhas do sistema de saúde. Rio de Janeiro: Medbook, 2008. 
GARGARELLA, R. Crisis de representación y constituciones contramayoritarias. Revista de Teoría y Filosofía del Derecho, n. 2, 1995.

GARGARELLA, R. Full representation, deliberation, and impartiality. In: ELSTER, J. Deliberative democracy. Cambridge: Cambridge University Press, 1998.

GARGARELLA, R. Theories of democracy, the judiciary and social rights. In: GARGARELLA, R.; DOMINGO, P.; ROUX, T. Courts and social transformation in new democracies. Hampshire: Ashgate, 2006.

GAURI, V.; BRINKS, D. M. Introduction. In: GAURI, V.; BRINKS, D. M. (Eds.) Courting social justice: judicial enforcement of social and economic rights in the developing world. Cambridge: Cambridge University Press, 2008.

GAURI, V. A new policy landscape. In: GAURI, V.; BRINKS, D. M. (Eds.) Courting social justice: judicial enforcement of social and economic rights in the developing world. Cambridge: Cambridge University Press, 2008.

GEORGE, A. Accountability in health services: transforming relationships and contexts. Harvard Center for Population and Development Studies, v. 13, n. 1, 2003.

GLOPPEN, S. Courts and social transformation: an analytical framework. In: GARGARELLA, R.; DOMINGO, P.; ROUX, T. Courts and social transformation in new democracies. Hampshire: Ashgate, 2006.

HOFFMAN, F. F.; BENTES, F. R. N. M. Accountability for social and economic rights in Brazil. In: GAURI, V.; BRINKS, D. M. (Eds.) Courting social justice: judicial enforcement of social and economic rights in the developing world. Cambridge: Cambridge University Press, 2008.

HUNT, P. et al. Neglected diseases: a human right analysis. Special topics in social, economic and behavioural research report series. n. 6. World Health Organization on behalf of the Special Programme for Research and Training in Tropical Diseases, 2007.

LABRA, M. E. Conselhos de Saúde: dilemas, avanços e desafios. In: LIMA, N. T. (Org.) Saúde e democracia: história e perspectiva do SUS. Rio de Janeiro: Fiocruz, 2005.

LAPALOMBARA, J. Interesses e pressões políticas. In: LAPALOMBARA, J. A política no interior das nações. Brasília: UnB, 1982. 
LEITE, F. Estados tentam barrar remédio via Justiça. Folha de S.Paulo, São Paulo, 03.10.2005. Disponível em:

http://www.sistemas.aids.gov.br/imprensa/Noticias.asp?NOTCod=67274. Acesso em: 25.11.2007.

LEVIN, J.; FOX, J. A. Estatística para ciências humanas. 9a ed. São Paulo: Pearson Prentice Hall, 2004.

LOPES, J. R. L. Direitos sociais: teoria e prática. São Paulo: Método, 2006.

MATTOS, P. T. L. Regulação econômica e social, accountability e democracia: contexto e perspectivas do debate. Revisa Direito GV, especial 1, 2005.

MERCURO, N.; MEDEMA, S. G. Economics and the law: from Posner to postmodernism. New Jersey: Princeton University Press, 1999.

MESSEDER, A. M. et al. Mandados judiciais como ferramentas para garantia do acesso a medicamentos no setor público: a experiência do Estado do Rio de Janeiro, Brasil. Cadernos de Saúde Pública, v. 21, n. 2, 2005.

OLIVER, T. R. The politics of public health policy. Annual Review Public Health, v. 27, p. 195-223, 2006.

PIETERSE, M. Social movements, and rights-based litigation in South Africa. Journal of Law and Society, v. 35, n. 3, p. 379, 2008.

PREFEITURA do Município de São Paulo. Desigualdade em São Paulo: o IDH. Secretaria do Desenvolvimento, Trabalho e Solidariedade, São Paulo, 2002.

ROSENBERG, G. The hollow hope: can courts bring social change? Chicago: The University of Chicago Press, 1993.

SANTOS, B. S.; AVITZER, L. Introdução: para ampliar o cânone democrático. In: SANTOS, B. S. (Org.) Democratizar a democracia: os caminhos da democracia participativa. Rio de Janeiro: Civilização Brasileira, 2002.

SALISBURY, R. Interest groups. In: POLSBY, N.; GREENSTEIN, F. (Orgs.) Handbook of Political Science. v. 4. Boston: Addison-Wesley Publishing Company, 1975.

SEN, A. Desenvolvimento como liberdade. São Paulo: Cia. das Letras, 2000. 
SHAPIRO, I. The state of democratic theory. Princeton: Princeton University Press, 2003.

SILVA, V. A. Taking from the poor to give to the rich: the individualistic enforcement of social rights. Disponível em:

http://www.enelsyn.gr/papers/w13/Paper\%20by\%20Prof.\%20Virgilio\%20Afonso\%20da\% 20Silva.pdf. Acesso em: 21.11.2009.

SUNSTEIN, C.; HOLMES, S. The cost of rights: why liberty depends on taxes. New York: Norton \& Company, 1999.

TERRAZAS, F. O Poder Judiciário como voz institucional dos pobres: o caso das demandas judiciais por medicamentos. Dissertação de Mestrado, Faculdade de Direito da Universidade de São Paulo. São Paulo, 2008.

THEODOULOU, S. Z. Making public policy. In: THEODOULOU, S. Z.; CAHN, M. A. (Eds.) Public policy: the essential reading. New Jersey: Prentice Hall, 1995.

TORTATO, M. Temporão acusa Justiça de tomar 'lugar dos médicos'. Folha de S.Paulo, São Paulo, 19.10.2007. Disponível em:

http://www1.folha.uol.com.br/folha/cotidiano/ult95u337955.shtml. Acesso em: 25.11.2007. TRAVASSOS, C. et al. Desigualdades geográficas e sociais na utilização de serviços de saúde no Brasil. Ciência \& Saúde Coletiva, v. 5, n. 1, p. 133-149, 2000.

UNITED NATIONS, Committee on Economic, Social and Cultural Rights, General Comment 9, The domestic application of the Covenant, U.N. Doc. E/C.12/1998/24. 1998.

VIANNA, L. W.; BURGOS, M. Revolução processual e democracia progressiva. In: VIANNA, L. W. (Org.) A democracia e os três poderes no Brasil. Belo Horizonte: UFMG; Rio de Janeiro: IUPERJ/FAPERJ, 2002.

VIEIRA, F. S.; ZUCCHI, P. Distorções causadas pelas ações judiciais à política de medicamentos no Brasil. Revista de Saúde Pública, v. 41, n. 2, p. 214-222, 2007.

VIEIRA, O. V. A desigualdade e a subversão do Estado de Direito. Revista Internacional de Direitos Humanos, v. 6, n. 4, 2007. 
WANG, D. W. L. A escassez de recursos como limitação para concretização de direitos (comentários a acórdão do STJ). Revista de Direito Público da Economia, v. 5, n. 20, p. 239-254, 2007.

Artigo recebido em 11/09/2009. Aprovado em 26/10/2009. 